\title{
EXPERIÊNCIA E CUIDADO DE SI: REFLEXÕES ACERCA DO SUJEITO NO ESPAÇO ESCOLAR
}

\author{
EXPERIENCE AND CARE OF SELF: reflections about the subject in the school \\ space
}

\author{
LA EXPERIENCIA Y EL AUTOCUIDADO: reflexiónes acerca del sujeto en el espa- \\ cio escolar
}

Waldênia Leão de Carvalho Professora Doutora da Universidade de Pernambuco - UPE. waldenialeao@gmail.com

\begin{abstract}
RESUMO: Quais os elementos necessários para que o pensamento possa realizar uma experiência educativa com ares de liberdade? Será possível que, na relação pedagógica entre o falante e o ouvinte, o dizer verdadeiro seja mais que conteúdo, seja o próprio movimento de encontro? Pensar nessas questões permite-nos percorrer o pensamento de Michel Foucault acerca da parrhesía. O encontro exige franqueza (parrhesía) entre seus pares e um exercício de reconstrução da palavra dita, da palavra ouvida em uma nova escrita que sai de si, mas se mantém fiel ao seu conteúdo primeiro. A fidelidade ou a veracidade está na capacidade de reescrevê-la, de reconstruí-la, de fazê-la sua, permitindo-se em processo de autoria. Assim, pensar na escola, em seus sujeitos e no trabalho de aprendizagem dos conteúdos é um convite a repensar a relação do aprender e do ensinar e as experiências de comunicação. Não se trata de apresentar um percurso metodológico, mas afirmar que há um movimento na linguagem dos sujeitos [escolares] e que tal movimento está ligado a um modo particular de lidar com a palavra; de fazê-la percorrer o caminho do diálogo e da autoria, percebida na transformação do silêncio em palavra e da palavra em silêncio. Por isso, mais que denominar o modo do fazer educativo [pedagógico ou psicagógico] ou traçar pontos de aproximação ou divergência, é preciso experimentar pensá-lo para fora dessa dimensão condutiva. Instaurar no trabalho educativo uma experiência que permita que cada um se deslocar na relação educativa, constituindo-se como um novo ser, do cuidado consigo, com o outro e com as coisas que as envolve.
\end{abstract}

PALAVRAS-CHAVE: Pensamento. Experiência. Pedagogia. Psicagogia. Michel Foucault.

ABSTRACT: Which elements are necessary to the thinking realise the educative experience with freedom? Is it possible that in pedagogic relation between speaker and listener, the said truth could be more than context or the proper meeting moviment? To think about these questions permit us to turn to Michel Foucault's thoughts in relation to parrhesía. The meeting among pairs is a said word reconstruction exercise from the listened word in a new writing that comes from self but keeps faithful to the first context. The fidelity or the truth is in the capacity of rewriting, rebuilt and make it yours by permiting yourself the authorship. To think about school, its beings and contexts learning work is an invitation to rethink the learning and teaching relation and the communication experiences. It does not mean to present the methodological way but to affirm that there is a language movement of [school] beings which is connected to a particular manner to deal with the word; to do it to pass the dialogue way and the authorship that is perceived in the word silence transformation and in the silence word. For this reason, more than denominate the educative way [pedagogic and psychologic] or to draw the approximation or divergency, it is necessary to expreriment and think about it out of the conductive dimension. To set up the educative work na experience that permit to each one to move in a educative relation to constitute as new being of self-care with other and the things which envolve it. KEYWORDS: Thought. Experience. Pedagogic. Psychology. Michel Foucault. 
RESUMEN: ¿Cuáles son los elementos necesarios para que el pensamiento pueda llevar a cabo una experiencia educativa con un aire de libertad? ¿Es posible que, en la relación pedagógica entre el hablante y el oyente, lo decir verdadero sea más que contenido, sea proprio movimiento de encuentro? Pensar en esas cuestiones nos permite irse al pensamiento de Michel Foucault sobre la parrhesía. El encuentro entre los pares es uno ejercicio de reconstrucción de la palabra dicha, de la palabra oída en una nueva escrita que sale de si, pero se mantiene fiel a su contenido primero. La fidelidad o la veracidad se encuentra en la capacidad de reescribirla, de reconstruirla, de hacerla suya, permitiéndose en proceso de creación propia. Pensar en la escuela, en sus sujetos y en el trabajo de aprendizaje de los contenidos es una invitación a repensar la relaciones de aprender y de lo enseñar y las experiencias de comunicación. No se trata de presentar uno camino o enfoque metodológico, pero afirmar que hay un movimiento en el lenguaje de los sujetos (escolares) que está conectado/unido a una manera de manosear con la palabra, de hacerla ir por el camino del dialogo y de la autoría, percibida en la transformación del silencio en palabra y de la palabra en silencio. Por ello, más que denominar o modo de hacer educativo (pedagógico o psicagógico) o delimitar puntos de aproximación o divergencia, se hace necesario experimentar pensarlo para fuera de esa dimensión conductiva. Instaurar en el trabajo educativo una experiencia que permita que cada uno se desplace en relación educativa, constituyéndose como un nuevo ser, del autocuidado de si, con el otro y con las cosas que las envuelve. PALABRAS CLAVE: Pensamiento. Experiencia. Pedagogía. Psicagogia. Michel Foucault. 


\section{1| INTRODUÇÃO}

O presente texto tem por objetivo refletir no conceito de experiência o processo de aprendizagem dos sujeitos no espaço escolar, com base na inserção do cuidado de si (epimeléia heautoû) como preceito capaz de potencializar a atenção e o olhar do sujeito sobre si mesmo e sobre sua formação [escolar].

Discutir as implicações para o pedagógico quando tomamos os elementos teóricos e práticos como partes inerentes do processo de aprender e ensinar, é transcorrer o pensamento que é, prioritariamente, um estado de conexão. Na escola, é preciso ampliar esta ligação [conceito/experiência], apoiando o deslocamento do ensino e do aprendizado, como caminho que possibilita aos estudantes uma experiência do pensamento.

Pensar a experiência, pensar a educação e, em especial, pensar a educação escolar e a formação dos sujeitos escolares, levam-nos a percorrer algumas ideias inseridas nos discursos educacionais, movimentando-se com base nas forças políticas e ideológicas que atravessam o fazer pedagógico. Muitas dessas forças esquecem que é a experiência e não a verdade, que dá sentido a escritura. Pois, lembrando o Michel Foucault, escrevemos para transformar o que sabemos e não para transmitir o já sabido.

Não há dúvidas de que ao longo da história da educação, muitas concepções foram surgindo e se consolidando, umas mais outras menos. Uma ideia, contudo, veio a partir dos aportes da Psicologia Educacional, unir nos processos educativos a noção de ensino e de aprendizagem, tornando-os em certa medida indissolúveis. Daí que é comum pensar: só se aprende aquilo que é ensinado. 0 aprendizado é um processo que se pode organizar. Organizar sua eficiência, controlar seus resultados. Assim, podemos tomar "o processo educativo numa perspectiva científica, dando segurança ao professor sobre como ensinar e como avaliar o aprendizado de cada aluno" (GALLO, 2012, p. 2).

Fazendoumaaproximação comoquefoidescrito, poderíamosiniciaresse diálogoobservandomuitos pontos. Mas, escolhemos começar com o pensamento tardio de Michel Foucault, especialmente com a inserção do conceito de cuidado de si (epimeléia heautoû) no âmbito pedagógico, ético e político. Durante muito tempo, o campo pedagógico esteve voltado para o ensino aprendizagem valendose da relação entre ciência e técnica ou entre ciência e verdade, excluindo muitas outras dimensões.

Debater a representação do pedagógico, suas categorias, seus conteúdos e seus discursos, não está para uma tarefa apenas teórica, nem para um exercício de pensar a teoria deslocada da prática ou vice-versa. É um esforço de estimular o pensamento, de reunir conceitos que se apresentam em campos aparentemente polarizados. Mesmo reconhecendo na prática a existência da realidade, sua legalização ou concretude está determinada pelas condições de agregar um número maior de defensores. Isto é, um número maior de pessoas que deem validade aos projetos de educação, de escola, de sujeito que se encontram em andamento.

Nos últimos anos, as teorias pedagógicas, enfatizam independentemente do viés de condução ideológica, que professor e aluno estão no centro do processo de ensino aprendizagem. São nesses sujeitos que todo o conhecimento transita. Fala-se do conhecimento produzido ao longo da história; do sujeito como construtor permanente do seu saber; da importância da curiosidade epistemológica; e, da afirmação de uma atitude de liderança frente aos desafios da vida como elementos essenciais para afirmação do sujeito moderno. Cada uma das características, esperadas para o sujeito do conhecimento, devem responder ao projeto no qual ele foi forjado. Isto significa, muitas vezes, responder aos desafios teóricos e práticos com que nos defrontamos dia a dia.

Nesse contexto, é de relevância perceber, na presença de características tão adversas, que há todo um estatuto político-pedagógico que dá suporte ao processo ensino aprendizagem, o qual acontece nas diversas práticas formativas realizadas nos mais diferentes espaços, em especial, o 
escolar. Nas instituições escolares, mais que em qualquer outro lugar, os paradigmas da ciência moderna encontram abrigo, revelando que a sociedade pôs na ciência toda sua expectativa de construção e renovação da vida. Ou seja, acredita que é pelo caminho da ciência e de seus métodos que não apenas compreendemos a vida, mas a produzimos.

Essa afirmação não causaria estranhamento para nenhum 'teórico' da educação em decorrência do fato de que a ideia está abrigada num caminho seguro, o da cientificidade. Portanto, a reprodução dos modos de fazer ciência para as novas gerações estaria resguardando o saber produzido e mantendo a continuidade de sua produção.

É importante reiterar que a consequência do rompimento das noções ou preceitos que se integram, o conhece-te a ti mesmo (gnôthi seautón) e o cuidado de si (epiméleia heautoû) atingiu o modo como pensamos o sujeito e sua constituição e o modo como nos relacionamos com o próprio conhecimento (FOUCAULT, 2006a, p. 3-24). Isso implica que, uma reconfiguração da relação pedagógica passa pelo exercício de trabalhar com o pensamento de modo a torná-lo mais potente. Restaurando a relação de aprendizagem ao longo da vida comprometida com o cuidado de si. Isto é, uma relação capaz de estabelecer com o saber uma aprendizagem na qual o ser se faz ou se revela. Não há dúvida de que esse ser em constituição precisa ser compreendido na trama histórica de sua construção.

\section{2| O HOMEM NA EPISTEME MODERNA}

Uma das questões mais provocativas para o estudo da constituição do homem é a conclusão que Michel Foucault tirou de suas investigações. O autor concluiu que, o surgimento do homem está ligado com a episteme moderna. Para ele,

Na experiência moderna, a possibilidade de instaurar o homem num saber, o simples aparecimento dessa figura nova no campo da epistemê, implicam um imperativo que importuna interiormente o pensamento; pouco importa que ele seja cunhado sob as formas de uma moral, de uma política, de um humanismo, de um dever de se incumbir do destino ocidental, ou da pura e simples consciência de realizar na história uma tarefa de funcionário; o essencial é que o pensamento seja, por si mesmo e na espessura de seu trabalho, ao mesmo tempo saber e modificação do que ele sabe, reflexão e transformação do modo de ser daquilo sobre o que ele reflete. (FOUCAULT, 2007, p. 451-452).

Em páginas anteriores do texto, o autor argumenta:

[...] o homem aparece com sua posição ambígua de objeto para um saber e de sujeito que conhece: soberano submisso, espectador olhado, surge ele aí, nesse lugar de Rei que, antecipadamente, Ihe designam Las meninas ${ }^{1}$, mas donde, durante longo tempo, sua presença real foi excluída. (FOUCAULT, 2007, p. 430).

Ainda, nas palavras do filósofo,

É uma criatura muito recente que a demiurgia do saber fabricou com as mãos há menos de 200 anos: mas ele envelheceu tão depressa que facilmente se imaginou que ele esperava na sombra, durante milênios, o momento de iluminação em que seria enfim conhecido. (FOUCAULT, 2007, p. 425).

\footnotetext{
${ }^{1}$ Tela de 1656 por Diego Velásquez.
} 
Por essa razão podemos esperar o seu desaparecimento final, não o homem como tal, mas como uma subjetividade moderna. Assim, a crítica de Foucault está voltada a qualquer teoria do sujeito que não leva em conta a teorização desse próprio sujeito.

Nos últimos anos de sua vida e sua obra, Michel Foucault se voltou a pensar com mais intensidade nas formas de constituir o sujeito na Antiguidade greco-romana como caminho para estudar o sujeito e os processos de sua subjetivação. Entre tantas reflexões realizadas, optamos por destacar as relações que foram estabelecidas com a educação acerca da constituição do sujeito. Assim, muitas das leituras sobre Foucault nos direcionam para a noção do cuidado de si com base no debate em relação à formação do sujeito e às práticas de subjetivação.

Certamente que uma crítica ao sujeito forjada na modernidade e as práticas pedagógicas fundadas numa pedagogia como saber e esta como verdade, não bastam para uma fuga da tradição de um fazer pedagógico que se volta para a produção do sujeito. Por isso, é necessário um compromisso com uma pedagogia que vise a uma transformação do sujeito por si mesmo. Talvez esse desejo seja mais uma tentativa de tratar da formação do sujeito tomando por base a retomada da experiência como fundamento do saber. Daí que pensar sobre os desafios da educação no presente não é um exercício de temporalidade, mas um recurso/fonte importante para o resgate da experiência, do sujeito de experiência.

Embora essas provocações possam parecer um tanto gerais, elas sugerem algumas condições para a ação de transformação do sujeito. Mas, antes, porém, de tratarmos dos resultados da separação entre ciência/conhecimento e sujeito/experiência, deixamos claro que o conceito de experiência que aqui nos dispusemos a discutir está atrelado a uma atenção que devemos estabelecer com as coisas ou com os acontecimentos que estão circundando nosso tempo e nossa vida. Isso significa que estamos valorando a(s) experiência(s) como uma ação de transformação do sujeito com base na abertura de si para si mesmo e para o mundo.

Se fortalecemos a ideia da experiência, compreenderemos que ela visa, portanto, completar o sujeito, permitindo que algo aconteça e, nesse acontecimento, o sujeito se transforme. É preciso lembrar que, para Larrosa (2002, p. 21), a experiência não está fundada num acúmulo de significados em que podemos dar às coisas. Ela é a possibilidade de que algo nos aconteça ou nos toque, requer um gesto de interrupção com a dinâmica que a vida [moderna] nos oferece.

Se isso basta como indicação, podemos afirmar que a ciência moderna estabeleceu uma relação com o sujeito do conhecimento um tanto divergente do que é necessário para haver uma situação de experiência desejada por Larrosa. Uma compreensão acerca desse afastamento entre ciência/conhecimento e sujeito/experiência pode ser observada nos escritos de Michel Foucault.

No curso livro A Hermenêutica do Sujeito, ao analisar os dois preceitos délficos: o conhece-te a ti mesmo (ghôthi seautón) e o cuidado de si (epimeléia heautoû), Foucault observa que o desequilíbrio e a supremacia do conhece-te a ti mesmo ocorreram quando no 'momento cartesiano' instaurou-se a evidência de origem. Ou seja, "a evidência tal como aparece, isto é, tal como se dá, tal como efetivamente se dá à consciência, sem qualquer dúvida possível” (FOUCAULT, 2006a, p.18). Assim, não haveria dúvida de minha existência como sujeito, nem necessidade de cuidar de mim mesmo enquanto ser.

Nesse caminho, o pensamento filosófico estaria albergado numa forma de pensamento que se interroga sobre o que faz com que haja e possa haver verdadeiro e falso e, ainda, "a forma como o pensamento que se interroga sobre o que permite ao sujeito ter acesso à verdade, forma de pensamento que tenta determinar as condições e os limites do acesso do sujeito à verdade" (FOUCAULT, 2006a, p. 19). 
A tensão sempre posta entre conhecimento de si e cuidado de si, estava no campo do pensamento filosófico moderno porque, segundo Foucault, houve, em algum momento da história do pensamento uma separação entre filosofia e espiritualidade. Assim, ele descreve: "Chamemos de 'filosofia', se quisermos, esta forma de pensamento que se interroga, não certamente sobre o que é verdadeiro e sobre o que é falso, mas sobre o que nos torna possível ou não separar o verdadeiro do falso" (FOUCAULT, 2006a, p. 19).

E ainda,

[...] poderíamos chamar de espiritualidade o conjunto de buscas, práticas e experiências tais como as purificações, as asceses, as renúncias, as conversões do olhar, as modificações de existência, etc., que constituem não para o conhecimento, mas para o sujeito, para o ser mesmo do sujeito, o preço a pagar por ter acesso à verdade. (FOUCAULT, 2006a, p. 19).

Dessa forma, a diferença entre filosofia e espiritualidade, empreendido por Foucault no curso livro A Hermenêutica do Sujeito, serviu para demonstrar que esta ocorreu na modernidade e não na antiguidade. Com esse rompimento, o sujeito não poderá acessar a verdade pela via única do conhecimento. Para o acesso seria necessário que o sujeito sofresse uma transformação. No processo de transformação, ele se tornaria, em certa medida e até certo ponto, outro que não ele mesmo (FOUCAULT, 2006a, p. 20).

O que está em jogo é muito mais do que a transformação do sujeito em um outro diferente. $\mathrm{O}$ que está em jogo é um modo de transformação. Assim, há algo mais profundo nessa conversão, que segundo Foucault pode ser feita através "de um movimento que arranca o sujeito de seu status e de sua condição atual" (FOUCAULT, 2006a, p. 20).

Até agora, limitamo-nos a colocar, em evidência, certas ideias e/ou argumentos que nos permitem estabelecer um diálogo entre o conhecimento e o sujeito. Contudo, para avançar nessa reflexão e aproximar nosso pensamento dos sujeitos escolares e das práticas que circulam em seus processos de ensino aprendizagem, recorremos, novamente, a Michel Foucault. Ele nos lembra de que submeter alguém à prova da realidade contemporânea é trabalho da filosofia, na medida em ela tem como tarefa diagnosticar e não dizer uma verdade. Implica também um entendimento de si enquanto sujeito de ação. Para efetivar, porém, essa ação, é necessário restaurar a presença do diálogo e do outro nos espaços desse fazer formativo, em virtude do compromisso que se reata na relação entre professor e aluno.

Cada um parece estar voltado a superar os limites em que se encontram e, para isso, estabelecem diferentes estratégias sem, contudo, prescindir da presença do outro. Nada se pode fazer sem o outro. Aqui está estabelecido um caminho necessário à própria aprendizagem, à necessidade da presença do outro para quem devemos dirigir o nosso diálogo.

A tarefa dialógica exige a franqueza (parrhesía), o exercício do franco falar, uma vez que a relação do aprender e do ensinar precisa que a comunicação entre seus sujeitos esteja livre de ruídos, que podem prejudicar o conteúdo da comunicação. Assim, embora a noção de parrhesía esteja envolvida no movimento do mestre que tem a palavra, do discípulo que silencia para ouvir a palavra do mestre e vice-versa não é uma relação de dominação que se apresenta, mas um acordo que permite ambos falarem e serem ouvidos.

Assim como o discípulo deve calar-se para operar a subjetivação de seu discurso, o mestre, por sua vez, deve manter um discurso que obedece ao princípio da parrhesía, desde que pretenda que o que ele diz de verdadeiro torne-se enfim, ao termo de sua ação e direção, o discurso verdadeiro subjetivado do discípulo. (FOUCAULT, 2006a, p. 440). 
Com base nessa referência, é possível compreender que o ato de falar e de ouvir implica o dizer verdadeiro, traduzido numa abertura e não numa imposição, pois há, nessa relação, um pacto fundamental para que o falante que toma a palavra diga o verdadeiro, porque o crê ser verdadeiro; e, também, ouvindo, acredite nesse dizer verdadeiro para que sua escrita possa traduzir uma verdade de sua escuta. O que importa aqui é dizer, então, que, dentre essas "condições e regras" que determinam o jogo de uma relação de aprendizagem dialógica, está a reescrita da palavra como uma nova autoria.

É importante retomar, nos escritos de Arrianus, ouvinte de Epicteto, um exemplo da reconstrução, que é possível ser feita, no processo de audição da palavra do outro [mestre, professor, amigo] (FOUCAULT, 2006a, p. 440-443). Arrianus ao escutar Epicteto, tomava notas [hypomnémata] e decidia publicá-las para que houvesse uma versão sua, uma passagem da audição à escrita. Essa nova escrita, resultante e representante da passagem de um estado de audição, não apenas pode ser reconhecida como uma condição daqueles que estão envolvidos pela veracidade do diálogo estabelecido, mas a reafirmação da potencialidade que o dizer verdadeiro é capaz de promover. Na medida em que a passagem de um estado de ouvinte para o de falante e a passagem de ouvinte para de escritor, torna quem ouve um novo autor. Autor de uma nova escrita, de uma escrita autoral.

Arrianus assim descreve o percurso de uma escrita autoral: "Quanto a tudo o que ouvi deste homem enquanto ele falava, esforcei-me, tendo-o escrito" (FOUCAULT, 2006a, p. 441). Para Michel Foucault, esse é um exemplo técnico, prático e real da possibilidade do exercício da parrhesía [do franco falar], de permitir aos seus sujeitos o movimento de transformação e porque não, da permanência de um conteúdo de verdade. Assim, ele o descreve:

Temos aí, pois, a escuta da palavra. Ele escuta, em seguida, escreve. Tendo escrito tanto quanto possível com seus próprios termos, com suas próprias palavras - emprega o termo ónoma - "tendo transcrito com as próprias, tentei conservá-las emautô (para mim), eis hýsteron (em vista do futuro) sob a forma de hypomnémata" [espécie de anotações de coisas ditas]. (FOUCAULT, 2006a, p. 441).

Mais à frente ele continua:

Arrianus insiste no fato de que ele realmente retomou "as próprias palavras". E constitui os hypomnémata, espécies de anotações de coisas ditas. Ele os constitui heautô (para ele próprio), eis hýsteron (em vista do futuro), isto é, em vista precisamente de constituir uma paraskeué (um equipamento) que lhe permitirá utilizar tudo aquilo quando a ocasião se apresentar: acontecimentos diversos, perigos, infortúnios, etc. (FOUCAULT, 2006a, p. 441)

A linguagem [escrita e falada] na forma como se institui e é valorizado, tem uma função no conhecimento escolar. Por isso, é certamente um assunto caríssimo à escola, porque seu espaço deve se constituir como um lugar destinado a uma prática de linguagem que fecunde o logos, a fim de que este se utilize de uma léxis (uma maneira de dizer as coisas) capaz de estabelecer certas relações e compromissos com o outro e com as coisas que o envolvem, de modo a superar a técnica e afirmar a arte, uma arte de existência. Talvez se abra aí uma espécie de liberdade pedagógica, em que o silêncio do discípulo seja fecundo, capaz de abrigar as palavras da verdade que são do mestre, e ele possa fazer dessas palavras verdadeiras algo de seu, que o habitará e o tornará ele próprio sujeito de veridicção (FOUCAULT, 2006a, p. 442). 
Nesse ponto, cabe relembrar a ideia de que, "do lado do mestre, haja um certo número de regras, regras que, uma vez mais, incidam não sobre a verdade do discurso, mas sobre a maneira pela qual o discurso de verdade será formulado" (FOUCAULT, 2006a, p. 442-443). A ideia de que a linguagem esteja de acordo com a conduta pode ser potencializada na medida em que nossos discursos tendam não ao agradável, mas ao útil. Aqui compreendido enquanto capaz de ser submetido à experiência, representante do encontro do aprendido com uma ação de intervenção, podendo ser esta ação consigo mesmo [uma ação de cuidado de si] ou como uma ação de intervenção no mundo [cuidado com o outro e com as coisas]. "É na experiência que se medirá a eficácia, a utilidade da palavra ouvida" (FOUCAULT, 2006a, p. 489).

No livro O governo de si e dos outros, na aula de 02 de março de 1983, ao tratar da parrhesía socrática, Foucault (2010b) afirma que ela não representa um dizer a verdade no campo político, mas uma ruptura em relação à atividade política propriamente dita. Segundo ele, há uma parrhesía propriamente filosófica que podemos conhecer, quando no texto Apologia, Sócrates fala da tarefa que Ihe foi confiada pelos deuses. Tarefa na qual guia sua vida e o põe como ouvinte [de todos aqueles que o queiram escutar] e, em seguida, como falante. Papel secundário, mas não menor, que permite a ele incitar cada um a ocupar-se de si mesmo [epiméleia heautôn].

\begin{abstract}
E se ocupar de si mesmo consiste, primeiramente e antes de mais nada, em saber se sabemos mesmo o que sabemos ou não. Filosofar, se ocupar de si mesmo, exortar os outros a se ocupar deles mesmos, e isso escrutando, testando, provando o que sabem e o que não sabem os outros, é nisso que consiste a parrhesía filosófica, parrhesía filosófica que se identifica, não simplesmente com um modo de discurso, com uma técnica de discurso, mas com a própria vida. (FOUCAULT, 2010a, p. 296).
\end{abstract}

A presença do discurso que não carrega o desejo da persuasão, mas de ruptura, pode ser melhor compreendida quando Foucault (2011, p. 297) afirma ser um discurso "que não cessa de se experimentar a cada instante, tanto naquele que o pronuncia como aquele a quem dirige". Parece ser esse fio condutor o elemento que concebe ao discurso o potencial de verdade. Esta compreendida como a ligação de todo processo, ou seja, "o discurso será uma verdadeira arte, contanto que a verdade seja uma função permanente do discurso" (FOUCAULT, 2011, p. 301).

Trata-se de apresentar as rupturas com o discurso envolvido por uma retórica e, dessa forma, possibilitar um duplo movimento: o movimento da alma que poderá ter acesso ao conhecimento do Ser e no conhecimento do que é a alma, ela conhecer a si mesma (FOUCAULT, 2011, p. 304). A conexão entre o discurso e a verdade põe em equilíbrio o conhecimento e o poder que advém desse saber.

Diria, assim, que é a questão de uma experiência do pensamento que está em jogo. Não se trata de apresentar um percurso metodológico, mas de dizer que há um movimento na linguagem dos sujeitos escolares, e que esse movimento está ligado a um modo particular de lidar com a palavra; de fazê-la percorrer o caminho do diálogo e da autoria. Percebida pela transformação do silêncio em palavra e por que não, da palavra em silêncio. Ou como nos lembra Foucault (2006a, p. 491), "é necessário que a parrhesía, a verdade daquilo que ele diz, seja selada pela conduta que ele observa e pela maneira como efetivamente vive".

\title{
3 | APENAS UMA PALAVRA BASTA PARA UM BOM APRENDIZ
}

Quando pensamos no processo de ensino da escola, não apenas com seus conteúdos científicos, mas como uma ação de transformação do sujeito, logo do outro e do(s) mundo(s) que os envolvem, nada como esperar que as relações estabelecidas estejam pautadas em atos de 
veridicção. Ou seja, que estejam embasadas nos ensinamentos e nas aprendizagens que corroborem para certo pacto entre o sujeito da enunciação e o sujeito da conduta, na medida em que cada um, falante ou ouvinte, se comprometa em realizar o falado, seja este fruto imediato da palavra, ou processo de sua transformação.

Ao contemplar esse movimento entre palavras e silêncios em seu conteúdo de verdade, não nos é permitido refletir sobre o ensinamento de verdade sem aquele que diz a verdade dê exemplo dessa verdade. "E o que autentica o fato de dizer-te a verdade é que, como sujeito de minha conduta, efetivamente sou, absoluta, integral e totalmente idêntica ao sujeito de enunciação que eu sou ao dizer-te o que te digo" (FOUCAULT, 2006a, p.492).

Foucault intensifica essa análise da parrhesía ao perceber a força do significado e da separação entre a transmissão da verdade e a relação que podemos estabelecer com ela. Imagino que, neste texto, essa reflexão amplie a compreensão não só de como funciona o campo da comunicação, mas de como se operam, no nível de enunciado, as inter-relações discursivas.

Mais uma vez é preciso que se diga: Foucault está a nos provocar com os textos da antiguidade (Epicteto, Sêneca, Galeno) a pensar na parrhesía e, nesse caminho, nosso desafio é pensar em um contexto pedagógico.

Não é nada fácil superar as fronteiras de um ensino condutor de verdades. Daí que as provocações de Michel Foucault sobre pedagogia e psicagogia são tão fundamentais para repensar as experiências que o pensamento estabelece com os sujeitos no espaço escolar.

Em outras palavras: trata-se de perguntar, no âmbito escolhido de nosso estudo, como o trabalho pedagógico pode operar a afirmação de uma relação com o conhecimento e com a vida, de modo intenso e verdadeiro, capaz de desconstruir estratégias de dominação e opressão sobre o pensamento e a ação de quem ensina e de quem aprende?

O que Foucault nos apresenta como diferencial ou talvez como passível de uma reflexão seja recuperada no debate que ele realiza em torno dos conceitos: pedagogia e psicagogia. Para 0 filósofo, o debate em torno do discurso verdadeiro sofreu transformações na história e, ao tratar desse tema, permite-nos pensar no sujeito, no conteúdo de sua aprendizagem e na ultrapassagem das duas formas visíveis do educar com ênfase no formar.

Sabemos que a ideia mais corriqueira que trazemos sobre o conceito de formar está fundada na transmissão de uma verdade e no trabalho de condução do ser educável (criança/jovem/educando/ aprendiz). Essa ideia aparece na maioria das experiências pedagógicas vividas por grande parte dos que estão em estado de aprendizagem; compreendida como aquisição de capacidades predefinidas, ditas "naturais" ao final da relação pedagógica que denominamos de Pedagogia.

Michel Foucault, no livro A Hermenêutica do Sujeito, ao apresentar a pedagogia afirma: "Chamemos, se quisermos, "de pedagógica" a transmissão de uma verdade que tem por função dotar um sujeito qualquer de aptidões, capacidades, saberes, etc., que ele antes possuía e que deverá possuir no final dessa relação pedagógica" (FOUCAULT, 2006a, p. 493).

O autor coloca em suspenso algumas discordâncias que podem povoar nosso pensamento neste momento, especialmente porque, há décadas, a pedagogia vem buscando superar seus limites e resgatar sua relação com o conhecimento, com o sujeito e com as formas de relação entre ambos. Nessa perspectiva, devemos tratar a ideia de como uma provocação do pensamento, nas construções históricas, o próprio pensamento promoveu.

As palavras de Foucault têm a função de retomar o percurso histórico, que provocou rompimento, e de apresentar outros conceitos que, embora no mesmo campo semântico, tenham sido separados, não se esqueceram de olhar com atenção o emissor do discurso verdadeiro. Assim, 
ele também, apresenta uma segunda forma que trata da relação do sujeito com a verdade, a Psicagogia. Ele diz: "podemos, creio, chamar "psicagogia a transmissão de uma verdade que não tem por função dotar um sujeito qualquer de aptidões, etc., mas modificar o modo de ser do sujeito a quem nos endereçamos" (FOUCAULT, 2006a, p. 493).

Se ambos os conceitos estão voltados à verdade, é porque partilham o mesmo modo de condução, diferindo apenas quanto ao objeto/estratégia do educar. A transmissão da verdade ocorreria desde a modificação do ser do sujeito, de início, pela via do mestre condutor, seguindo em direção à condução da alma (FOUCAULT, 2006a, p. 492).

A presença do cuidado de si põe em evidência a tarefa pedagógica como uma prática essencial para a constituição do sujeito por ele mesmo. Com isso, instaura a autoconstituição do sujeito com base em um processo de autoformação ou formação de si mesmo. Por esse motivo, Michel Foucault afirma a potência do conhecimento que modifica a maneira de agir, o que ele descreve como êthos.

No livro Governo de si e dos outros, Foucault (2010b) apresenta o saber e a prática pedagógica como vetores de transformação ética dos sujeitos. Daí a urgência da educação como arte de existência. Se essa ideia percorre todo o texto é porque na medida em que o termo Psicagogia é apresentado, aparece não apenas como um resgate histórico filosófico, mas como uma experiência de dessubjetivação. Movimento capaz de operar no sujeito as condições necessárias para que cada um possa realizar um discurso verdadeiro.

Assim, o cuidar de si operaria uma prática psicagógica que, deslocada para o âmbito do mestre-discípulo, exige um modo particular de relação, o que, sem dúvida, estaria numa relação erótica (de amor) na medida em que cria um modo singular de olhar e de ouvir a si mesmo e ao outro.

A estreita relação entre a Pedagogia e a Psicagogia, no período antigo, vai sofrer uma modificação com o cristianismo. Segundo Foucault (2006a, p. 494),

\begin{abstract}
A [psicagogia] greco-romana estava ainda muito próxima da pedagogia. Ela obedece à mesma estrutura geral, segundo a qual é o mestre que mantém o discurso de verdade. $\mathrm{O}$ cristianismo, por sua vez, irá desvincular a psicagogia, solicitando à alma - à alma que é psicagogizada, que é conduzida - que diga uma verdade; verdade que somente ela pode dizer, que somente ela detém e que não constitui o único, mas é um dos elementos fundamentais da operação pela qual seu modo de ser será modificado.
\end{abstract}

Mais importante que denominar os modos do fazer educativo [pedagógico ou psicagógico] ou traçar pontos de aproximação ou divergência, é experimentar pensá-lo para fora dessa dimensão condutiva. Instaurar no trabalho educativo [da escola] uma experiência que potencialize a aprendizagem e permita a cada um se ausente da relação educativa, constituindo-se enquanto autoria. É um desejo de reconstruir o conteúdo de verdade preservando a verdade do falante e do ouvinte.

\title{
4 | CUIDAR DE SI MESMO: uma experiência de transformação
}

É necessário, sem dúvida, antes de prosseguir no estudo sobre a constituição de si, voltar a situar novamente a formação no trabalho investigativo que Michel Foucault empreendeu sobre as noções greco-romanas do conhece-te a ti mesmo e do cuidado de si, caso se deseje pensar em toda a profundidade e abertura, que elas nos autorizam. Não há como negar que toda essa estrutura histórico-filosófica deixou marcas no trabalho de pensar a subjetividade. Por isso, devemos caminhar em dois sentidos: um de conhecimento e outro de experiência. No primeiro, vamos conhecer as fronteiras de um fazer que se impôs como o modo mais correto de pensar a subjetividade. No segundo, vamos pensá-lo como alternativa na tarefa de formação, buscando apreender outras formas de estar no mundo sem necessariamente ser absorvido pelo modelo predominante. 
Não se trata, porém, de valorizar tanto a prática em detrimento da teoria, com a desculpa de que poderíamos, quem sabe, visualizar melhor esse processo de constituição da subjetividade, tampouco valorizar o inverso alegando uma maior racionalidade do processo. Trata-se de compreender os movimentos, pois ambos dão lugar a um modo de conhecer e a uma elaboração do saber. Importante notar, entretanto, que a afirmação de uma prática-teórica ou uma teoria-prática não representou, no trabalho de Foucault sobre o cuidado de si, nenhum desdobramento significativo dos termos ou da relação estabelecida nesse contato. Sua intenção era sinalizar que o trabalho sobre si mesmo passa por exercícios e práticas que propiciam um modo de existência que, para ele, deve estar marcada e marcando a própria vida. Como explica Foucault (2006a, p.11),

O cuidado de si é uma espécie de aguilhão que deve ser implantado na carne dos homens, cravado na sua existência, e constitui um princípio de agitação, um princípio de movimento, um princípio de permanente inquietude no curso da existência.

Ao dizer sim à existência e vivê-la de modo diferente, convida-nos Foucault. Atender a esse convite é um bom começo para experimentar outros modos de vida.

\section{5| ALGUMAS CONSIDERAÇÕES...}

Parece apropriado concluir que este texto expôs as investigações de Michel Foucault sobre a parrhesía, não apenas descrevendo o olhar sobre um conceito da antiguidade grega mas, no esforço de pensar o pedagógico, atravessado por um outro modo de pensar a formação do sujeito [escolar]. Ele nos convida a tomar o diálogo pedagógico como espaço de reconstrução da aprendizagem de seus sujeitos. Este é um tema importante porque justamente a comunicação entre docente e discente é um dos pontos de maior fragilidade quando buscamos ultrapassar um ensino e uma aprendizagem com ares formativos, aqui compreendidos na intenção de oferecer um número cada vez maior de informações ao seu aprendiz, acreditando ser esse processo o único caminho capaz de permitir a concretização dos objetivos pedagógicos. Por isso, é uma razão mais que importante para justificar o motivo pelo qual a comunicação [linguagem] importa para a educação.

Michel Foucault em suas obras As palavras e as coisas e Arqueologia do saber, estava atento as tensões entre as tendências formalistas e interpretativas que dominavam o tratamento da linguagem no século XX (CASTRO, 2009, p. 251). Seu trabalho, portanto, não se fixa no ser da linguagem, mas no seu uso e na sua prática. Isto é, a racionalidade que organiza o que os homens fazem.

Um dos traços que mais chama atenção, ao analisar o conjunto de conexões [teórico/prática] selecionadas ao longo do texto, é que desde o horizonte grego, as inovações não podem prescindir de práticas ou exercícios de afirmação de uma ética do eu. O próprio Foucault (2006a, p. 306) reconhece certa impossibilidade de fazê-lo sem fornecer conteúdos para as práticas e/ou exercícios de autoformação.

As palavras de Foucault ecoam para nos recordar de que a responsabilidade educacional requer uma abertura do sujeito ao seu próprio cuidado. Não podemos esquecer que, essa tarefa de cuidar do pensamento, de potencializá-lo está de fato atrelada à noção de parrhesía, ou seja, o dizer-a-verdade uma vez que seu sentido articula o modo do indivíduo se constituir como sujeito e na relação com os outros (FOUCAULT, 2010b, p. 42).

Por fim, ressalto que não seria possível perceber essa contribuição ou esse desafio que uma prática do diálogo impõe aos seus participantes se ela não estivesse sendo construída com base no movimento em torno da inquietação do indivíduo sobre si mesmo. Foucault (2006a, p. 103) nos 
mostra que o olhar sobre si deve ser percebido numa amplitude e profundidade que supera a presença de um conjunto de práticas, formas de vida ou modos de existência. Isso significa permitir, ser atravessado e manter consigo mesmo um permanente estado de zelo, cultivado por um contínuo exercício de preservação de si mesmo como uma escolha pessoal de vida.

Deixar a questão em aberto pode trazer perigos. No entanto, é preciso abertura para tratar com o pedagógico na medida em que se constitui enquanto espaço de constituição do ser. A escola e seus sujeitos precisam se sentir convidados ao encontro com uma forma de fazer-se presente na vida. O espaço existe, então, sejamos corajosos. 


\section{Referências}

CASTRO, E. Vocabulário de Foucault: um percurso pelos seus temas, conceitos e autores. Revisão técnica Alfredo Veiga-Neto e Walter Omar Kohan. Tradução Ingrid Müller Xavier. Belo Horizonte: Autêntica Editora, 2009.

FOUCAULT, M. A coragem da verdade: o governo de si e dos outros II. Tradução Eduardo Brandão. São Paulo: Editora WMF Martins Fontes, 2011.

A hermenêutica do sujeito. Tradução Márcio Alves da Fonseca e Salma Tannus Muchail. 2. ed. São Paulo: Martins Fontes, 2006a.

As palavras e as coisas: uma arqueologia das ciências humanas. Tradução Salma Tannus Muchail. 9. ed. São Paulo: Martins Fontes, 2007.

Ditos \& Escritos V: ética, sexualidade e política. Organização e tradução: Manoel Barros da Motta. Tradução Elisa Monteiro e Inês Autran Dourado Barbosa. 2. ed. Rio de Janeiro: Forense Universidade, 2006b.
Ditos \& Escritos VI: repensar a política. Tradução de Ana Maria Paranhos Pessoa. Rio de Janeiro: Forense Universitária, 2010a.

O governo de si e dos outros. Tradução Eduardo Brandão. São Paulo: Editora WMF Martins Fontes, 2010b.

GALLO, S. As múltiplas dimensões do aprender. In: CONGRESSO DE EDUCAÇÃO BÁSICA: APRENDIZAGEM E CURRÍCULO, 2., 2012, Florianópolis. Anais... Florianópolis: UFSC, 2012. p. 1-10. Disponível em: $\quad<$ http://www.pmf.sc.gov.br/arquivos/arquivos/ pdf/13_02_2012_10.54.50.a0ac3b8a140676ef8ae0dbf32e662762.pdf>. Acesso em: 08 out. 2015.

LARROSA, J. Notas sobre a experiência e o saber de experiência. Revista Brasileira de Educação, Rio de Janeiro, n. 19, jan./fev./mar./abr. 2002. Disponível em: <http://www.scielo.br/pdf/rbedu/n19/n19a02.pdf>. Acesso em: 10 out. 2015. 